\title{
Back to the future?
}

\author{
Author: Douglas Seaton ${ }^{\mathrm{A}}$
}

The author reflects on his personal experience of some of the changes that have affected the NHS over the last four decades and expresses his concern about its current direction of travel. Douglas Seaton trained in Liverpool and Morgantown, West Virginia. He was appointed as a consultant in general and respiratory medicine at Ipswich Hospital in 1978, and retired from clinical practice in 2006.

KEYWORDS: NHS, retrospective, health strategy

In the successful film Back to the Future (1985), the hero was able to alter the future by travelling back in time. In this piece, I have been asked to travel back in time. In doing so, I won't alter the future of the NHS, but general medical opinion will if convincing arguments are voiced for the highest possible standards.

When my classmates and I qualified from medical school in 1970 , the only requirements for full registration were two 6-month house officer posts, one in medicine and one in surgery. We were expected to look reasonably tidy, wear clean white coats, carry a stethoscope and try to meet our forgiving patients' expectations of how a competent doctor should behave. We didn't think of ourselves as trainees but rather as junior doctors who were working in a demanding job and learning in that process. There was no concept of overtime. We had been taught how to clerk and examine patients when we were students, and with increasing practice became better at it. We learned new practical skills as and when needed from our registrars and, in time, passed these skills onto those coming after us. We became used to presenting cases at grand rounds and to accepting criticism. The only external instruction I had was a revealing course run over a couple of days that taught examination techniques for passing the second part of the MRCP(UK), which then consisted of a long case, short cases and a viva.

As our experience increased, we found that publications were also necessary to demonstrate a methodical approach to clinical medicine and we looked for jobs in which clinical research would be encouraged. It was possible to achieve all this within the NHS if the right chief took you on. A period abroad also helped, usually in an academic hospital in the USA, where

Author: ${ }^{\text {A }}$ consultant physician (retired), General and Respiratory Medicine, Ipswich Hospital, Ipswitch, UK. there was less clinical pressure and more time for writing up a thesis and becoming involved in further studies. How long this whole process took depended on a combination of motivation and luck; whether the right job came up at the right time and whether you were fortunate enough to be appointed. There was no defined point at which we were thought to be 'trained', but as a senior registrar it became clear when the time was ripe to think about applying for a consultant position.

I took up my first and only consultant post aged 33 working between three hospitals in the same town. I had less general medical experience than many senior registrars, but retained a capacity to learn on the job. With overall responsibility for patients, the crucial importance of the team structure that I had previously been a part of was obvious. This staffing arrangement had not changed much since the early days of the NHS with a pre-registration house physician (currently known as foundation year 1), a senior house officer ( $\mathrm{SHO})$, and a registrar (or sometimes a more experienced $\mathrm{SHO}$ ) working with each consultant. Patients admitted under a given consultant remained under his or her care throughout their stay, often with outpatient follow-up for as long as necessary. Referrals were often from general practitioners (GPs) who frequently had close, personal knowledge of their patients. ${ }^{1}$ A GP with a patient who had an identifiable subspecialty problem would make the appropriate referral, but when things were unclear a generalist approach was valued, and such cases would often provide the whole team with interesting and educational clinical challenges. The hospital attracted job applications from promising juniors. My senior colleague and I had an arrangement with one of the London clinical schools, whereby we recruited house physicians by informal interview at the school itself. They would rank us, and we them, and we were seldom disappointed by the outcome. The hospital's medical SHO rotation was also popular, and had a reputation for success in the MRCP(UK). The consultants ran a weekly clinical MRCP class, although a wellappointed and friendly doctors' mess was also part of the draw. Within a few years the three hospitals merged into a large district general hospital on one site, which was sufficiently distant from the next centre to enable continued development of good facilities. In our own specialty we had a purpose built chest clinic with an adjoining exceptionally well staffed and fully equipped lung function unit. This latter unit had been built up and managed over the years by a talented and highly committed associate specialist colleague who had established a niche for himself in respiratory physiology. It was possible to maintain these high standards and to use this facility for small clinical research projects, in which our registrars could 
get involved, leading to publications. I do not intend to paint an idyllic picture: the work was hard, with busy takes and large clinics, but we managed. The small-team structure produced a sense of belonging, a modest esprit de corps and a degree of mutual support. $^{2}$

As time went on, we tried to preserve this small-team structure. When on call, you knew your colleagues and their levels of experience, and could tailor support accordingly. There were at first no serious shortages of beds. However, national pressures to reduce expenditure on ward staff resulted in reduced bed numbers, while the size and median age of the acute takes grew. Increasingly, patients would overflow into the beds of other specialties, resulting in disruption and drawn-out ward rounds that forced us to change how we worked. Acute admissions were then directed to the now-familiar medical admissions unit, where the on-call team received them. The following day, they would be transferred, if possible, to a specialty ward. At that point the admitting team would in many cases hand over to another team, and continuity of care, which had been a lynchpin of the earlier general medical system, was broken. Patients who found their way from the generalist admission team to the appropriate specialist ward would be likely to benefit, but those often elderly patients with multiple system issues were at risk of harm unless handover to another ward-based team was faultless.

The perceived advantages of the small-team structure came under further threat as a result of central direction to limit the number of hours that junior doctors worked. There was suspicion that these moves were not altruistic, but rather intended to save money because the British Medical Association had negotiated that salaries should reflect not only grade and seniority, but also hours on call. We circumvented full shifts for a few years by merging our on-call commitments with those of our geriatrician colleagues and having a small group of SHOs devise a new rota that was compliant while preserving the small-team structure. We fancifully called it a 'modified partial shift system', which we continued until tightening of the European Working Time Directive forced the adoption of genuine shifts.

Although acute takes were no longer kept within the team, it was possible to maintain morale with strong ward-based teams and to use some of the pressures of the acute takes for the general good. We established a six-bed acute respiratory care unit in a bay of our respiratory ward with a high dependency level of trained nurses to provide non-invasive ventilatory support for defined groups of patients with respiratory failure. This development was backed by not only our physician colleagues but also the intensive-care-unit staff, who saw that it would ease pressure on their unit by reducing admissions and enabling step down for some of their patients. The acute respiratory care unit necessitated a separate one-in-four oncall commitment for senior respiratory physicians, and has continued for well over a decade.

During my 27 years in the same post, senior staffing levels changed, although the number of trainees remained fairly constant. I was never single-handed and for almost the whole period there were two respiratory consultants who also worked as generalists, one attached to each junior team. In my last five years in post, the consultant number increased to three. Rather than break up the junior teams, we arranged for the three of us to work equitably between the two trainee teams, each senior being attached for ward work to one team for 2 months, followed by a fallow period before returning for a further two months with the second team in strict rotation. An associate specialist provided valuable support, and more recently that post has metamorphosed into a fourth consultant position.

The provision of ward nursing was always stretched, particularly at night. A good ward sister was valuable beyond measure, attracting a better team and maintaining morale. The introduction of specialist nurses also raised standards, but the removal of student nurse training from the wards to schools of nursing seemed to be retrogressive. Throughout all this, our patients, on whom the whole effort was centred, were almost always extremely tolerant and forgiving of a stretched health service with its constrained economic fortunes. The same tolerance was less frequently shown by their younger relations, whose expectations sometimes more closely reflected the loudly trumpeted but unfulfilled claims for the NHS of politicians seeking re-election.

Our hospitals are now frequently described as trusts, although an observer on the sidelines might think that trust in the medical workforce to carry out its responsibilities is paradoxically lacking. It might seem that consultants are no longer relied on to keep themselves up to date and to behave properly without having to repeatedly collect written evidence to that effect. It might also seem that seniors are no longer trusted to oversee their juniors' training to a satisfactory level without the requirement to sign off every little waymark on the path to specialist accreditation. There is a truth based on common sense that excessive attention to detail can distract from the general overview. Let's not forget the scale of the Medical Training Application Service debacle. ${ }^{3}$

There are other threatening distractions. Business people promote the advantages of deregulation, but the forces of the open market present doctors in the NHS with a grave burden. Legislation encouraging commercial competition for clinical services that are funded by general taxation is upon us and business terms such as 'internal market', 'purchasers and providers', 'commissioning groups', 'standard tariff' and so forth have been introduced on business lines to a service that was never intended to operate at a profit. Is there evidence that private enterprise intent on profiting from NHS expenditure will provide a better clinical service and value for money? Or is it more likely that such entrepreneurial competition represents an existential threat to the NHS provider concerned primarily with the provision of good patient care and with it opportunities for training and research within a given budget? Should the fact that one of the country's foremost academic dermatology departments has suddenly disappeared in the face of commercial competition not stir the sleeping collegiate giant from its slumbers? ${ }^{4}$

Throughout my working life and beyond, there have been continued medical advances and the NHS has reflected these successes by providing a marvellous service despite reorganisations and tight budgetary restraint. ${ }^{5} \mathrm{I}$ hope, notwithstanding the inevitability of change, that more trust will be placed in the medical profession as a whole and that its leadership will rise above the daily distractions of 'Yes Minister' detail and be firm, fearless, open and vocal in providing constructive criticism and guidance to the 
profession, the public and those who are answerable to the electorate.

\section{References}

1 Marshall M. A precious jewel - the role of general practice in the English NHS. New Eng J Med 2015;372:893-7.

2 Seaton D. A memorable ward round. BMJ 2009;338:879.

3 Armitage M. Going to the dark side: clinicians, leadership and the Department of Health. Clin Med 2008;8:589-91.
4 Iacobucci G. Transfer of services from NHS to private provider was "unmitigated disaster," report says. BMJ 2015;350:h3161.

5 Delamothe T. A centrally funded health service free at the point of delivery. BMJ 2008;336:1410-2.

Address for correspondence: Dr D Seaton, 23 Park Road, Ipswich IP1 3SX, UK.

Email: seatons@btinternet.com
Assessing trainees in the workplace An e-learning module for secondary care doctors

Three hours of CPD-approved interactive learning covering:

$>$ feedback

> supervised learning events (SLES)

$>$ workplace-based assessments (WPBAs)

$>$ the role of the Annual Review of Competence Progression (ARCP).

For more information please visit: www.rcplondon.ac.uk/elearning

\section{Royal College} of Physicians

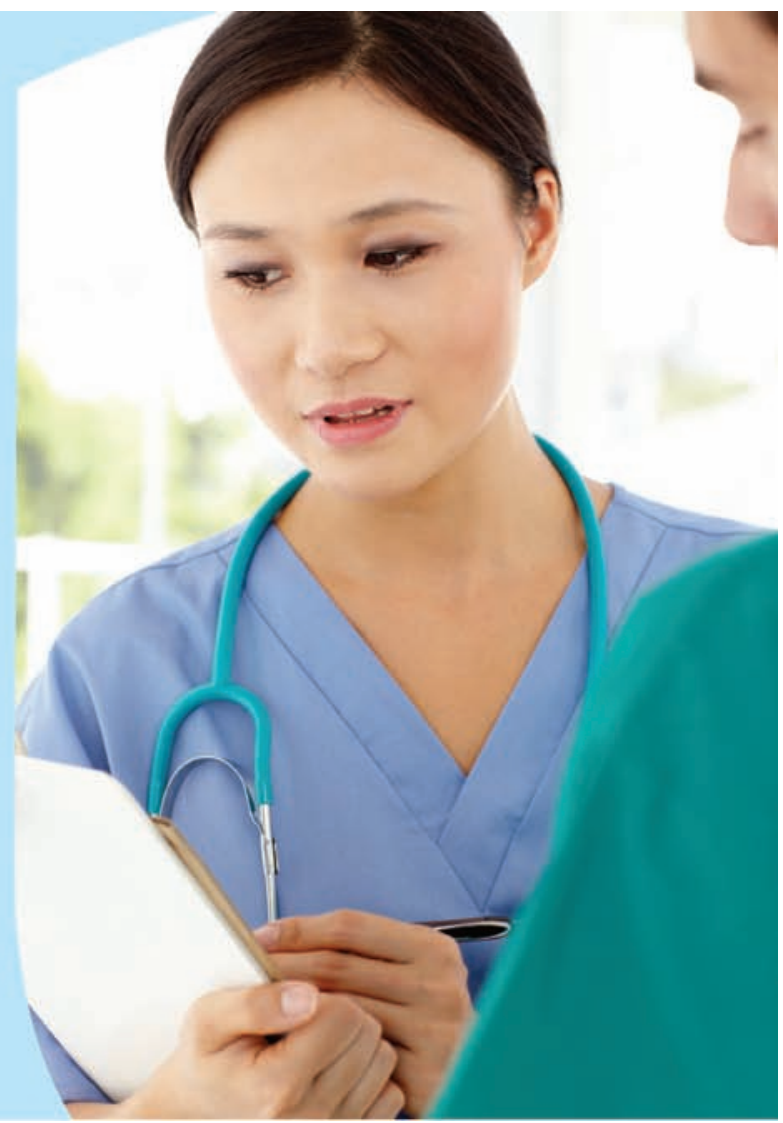

